\title{
Community metabarcoding uncovers vast diversity and a lack of barcode references for aquatic invertebrates in Carpathian spring fens
}

\author{
Magdalena Gajdošováł, Arne Beermann§, Jindřiška Bojkovál, Vendula Poláškovál, Jana Schenkovál, \\ Marie Zhail, Michal Horsákl, Florian Leese ${ }^{\S}$, Adam Petrusek ${ }^{\ddagger}$ \\ ‡ Faculty of Science, Charles University, Prague, Czech Republic \\ $\S$ Faculty of Biology, University of Duisburg-Essen, Essen, Germany \\ | Faculty of Science, Masaryk University, Brno, Czech Republic
}

Corresponding author: Magdalena Gajdošová (magdalena.gajd@gmail.com)

Received: 25 Feb 2021 | Published: 04 Mar 2021

Citation: Gajdošová M, Beermann A, Bojková J, Polášková V, Schenková J, Zhai M, Horsák M, Leese F, Petrusek A (2021) Community metabarcoding uncovers vast diversity and a lack of barcode references for aquatic invertebrates in Carpathian spring fens. ARPHA Conference Abstracts 4: e65057. https://doi.org/10.3897/aca.4.e65057

\begin{abstract}
Recent studies on diversity of stream amphipods proposed that the Western Carpathians have served as an important glacial refugium of freshwater fauna. If this scenario is true, a considerably high molecular diversity can be expected in this biogeographic region also for other taxa. In our project, we aimed to uncover and characterize molecular diversity of benthic macroinvertebrate fauna of spring fens, a well studied and hence convenient model community. Using a DNA metabarcoding approach, we sequenced a fragment of the COI gene of pooled spring fen invertebrate communities from 21 localities in the Western Carpathians. The preliminary analysis of the sequences revealed a substantially higher amount of operational taxonomic units (OTUs), when compared to the number of taxa identified in the same spring fens based on morphological characters. The lack of reference sequences in public databases (Barcoding of Life Database, GenBank) for the majority of the detected OTUs indicates that the Western Carpathian region is not yet sufficiently covered by barcoding efforts, and suggests that there indeed may be a considerable unrecognized diversity of macrozoobenthos. However, most newly uncovered diversity is concentrated in a few taxa such as the dipteran families Tabanidae and
\end{abstract}


Ceratopogonidae, annelid species (complexes) Eiseniella tetraedra and Helobdella stagnalis or the amphipod genus Gammarus. In the future, these findings will be the basis for several levels of research: detailed investigation of seemingly hyperdiverse taxa (phylogeography, phylogeny, reference coverage) and comparison of overall molecular diversity of these communities in the Western Carpathians and neighbouring Bohemian Massif, a region where we expect much lower diversity due to different biogeographic history.

\section{Keywords}

cryptic diversity, Carpathians, macrozoobenthos, spring fens, metabarcoding

\section{Presenting author}

Magdalena Gajdošová

\section{Presented at}

1st DNAQUA International Conference (March 9-11, 2021) 